University of Nebraska - Lincoln

DigitalCommons@University of Nebraska - Lincoln

Educational Psychology Papers and

Publications

Educational Psychology, Department of

March 1998

\title{
Assumptions of Behavioral Consultation: After All Is Said and Done More Has Been Done than Said
}

Thomas R. Kratochwill

University of Wisconsin-Madison

John R. Bergan

University of Arizona

Susan M. Sheridan

University of Nebraska-Lincoln, ssheridan2@unl.edu

Stephen N. Elliot

University of Wisconsin-Madison

Follow this and additional works at: https://digitalcommons.unl.edu/edpsychpapers

Part of the Educational Psychology Commons

Kratochwill, Thomas R.; Bergan, John R.; Sheridan, Susan M.; and Elliot, Stephen N., "Assumptions of Behavioral Consultation: After All Is Said and Done More Has Been Done than Said" (1998). Educational Psychology Papers and Publications. 60.

https://digitalcommons.unl.edu/edpsychpapers/60

This Article is brought to you for free and open access by the Educational Psychology, Department of at DigitalCommons@University of Nebraska - Lincoln. It has been accepted for inclusion in Educational Psychology Papers and Publications by an authorized administrator of DigitalCommons@University of Nebraska - Lincoln. 
Published in School Psychology Quarterly, 13:1 (1998), pp. 63-80. Copyright (C) 1999 American Psychological Association. Used by permission. "This article may not exactly replicate the final version published in the APA journal. It is not the copy of record." http://www.apa.org/journals/spq/

Preparation of this article was supported by Grants H023C20172 and H029F30031 to the first author from the U.S. Department of Education, Office of Special Education and Rehabilitation Services, Washington, D.C. The views expressed in this article do not necessarily reflect those of the U.S. Department of Education and are solely those of the authors.

Special appreciation is extended to Karen O'Connell for her assistance with this manuscript. Corresponding author: Thomas R. Kratochwill, School Psychology Program, University of Wisconsin-Madison, 1025 W. Johnson Street, Madison, WI 53706-1796.

\title{
Assumptions of Behavioral Consultation: After All Is Said and Done More Has Been Done than Said
}

\author{
Thomas R. Kratochwill, Wisconsin Center for Education Research, \\ University of Wisconsin-Madison \\ John R. Bergan, University of Arizona \\ Susan M. Sheridan, University of Utah \\ Stephen N. Elliott, Wisconsin Center for Education Research, \\ University of Wisconsin-Madison
}

\begin{abstract}
The purpose of our article is to provide a reaction to the article by Noell and Witt (1996) regarding five fundamental assumptions underlying behavioral consultation, as well as react to a manuscript by Witt, Gresham and Noell (1996a) pertaining to their critique of some aspects of behavioral consultation. We provide a reaction to the alleged fundamental assumptions pertaining to consultation, specifically that (a) consultation is a superior use of resources when compared to direct intervention/therapy; (b) consultation is conducted collaboratively; (c) talking to teachers is sufficient to cause them to change their behavior; (d) teachers will generalize problem-solving skills developed in consultation to new problem situations with other clients; and (e) direct contact between the consultant and client is unnecessary. Issues surrounding future research in consultation are presented within the context of these two prior publications.
\end{abstract}


The purpose of this article is to respond to the critical re-evaluation of five fundamental assumptions underlying behavioral consultation as presented in Noell and Witt (1996). In addition, we react to an article by Witt, Gresham, and Noell (1996a) and their review and critique of behavioral consultation (see also Erchul \& Schulte, 1996; Witt, Gresham, \& Noell, 1996b). Many of the points raised in the two articles have been presented previously in the literature. For example, Witt and Martens (1988) discussed teacher skills and competencies pertaining to implementation of instructional interventions. Witt (1990) raised concerns over whether consultation and problem-solving strategies used within behavioral consultation should focus on addressing teacher verbal complaining behaviors. Moreover, Gresham (1991) raised concerns over why functional analysis is not integrated within behavioral consultation. We would also add that some evolving ideas about behavioral consultation have been presented a few years ago (see Bergan, 1995; Kratochwill, Sladeczek, \& Plunge, 1995).

We appreciate the opportunity to respond to these previous publications because a number of important points have been raised that could influence the future direction of research and possibly practice. In fact, we hope that many of the points that we raise will clarify inconsistencies and inaccuracies that have been raised in the two articles. We also address issues for consideration by the authors and for individuals in the field who may be interested in future research on behavioral and other models of consultation. The issues presented in our manuscript address primarily the five fundamental assumptions raised by Noell and Witt. We were invited to react to the Noell et al. manuscript in the Journal of Educational and Psychological Consultation and had prepared a brief reaction for that journal. Upon publication of the Noell and Witt (1996) article in School Psychology Quarterly, however, we withdrew our earlier manuscript in order to integrate our reactions and avoid dual publication. Therefore, the current article represents a reaction to the issues raised in both articles.

\section{A PRIORI ASSUMPTIONS AND DEFINITIONS REVISITED}

To understand our reactions to the five assumptions underlying behavioral consultation and a critical analysis presented by the authors, it is important to revisit some of the evolving assumptions pertaining to the definition of consultation. Such a discussion should hopefully clarify issues pertaining to the fundamental assumptions and critical appraisal. More importantly, these assumptions should stimulate future thinking pertaining to how research on consultation is structured and the way that we conceptualize progress in the field of consultation.

Within school psychology, most authors have portrayed consultation as an indirect service delivery model in which a mediator works with a consultee with the purpose of changing the consultee and/or client. Within the behavioral consultation field, the strategy is contrasted to direct therapy techniques, although, as we will argue, these are often more dimensional issues than they are categorical con- structs guiding the behavioral therapy relationship. In 1990, Bergan and Kratochwill discussed two important points pertaining to this issue. First, we noted that the definition of consultation has been quite broad, thereby allowing inclusion of many procedures where there was indirect involvement of a consultant with a consultee. As an example of this relationship, we noted that the literature in behavior therapy is diverse and that many studies outside the school psychology literature (as we operationally define studies published in major school psychology journals) are often not included in reviews of behavioral consultation. For example, many studies published in the Journal of Applied Behavior Analysis, as well as many other behavior therapy oriented journals involve indirect service delivery techniques - and are often more generically called behavior modification or behavior therapy. Interestingly, this issue was conveyed in the definition of the 1990 Bergan and Kratochwill text, which readers will identify as "behavioral consultation and therapy."

In the context of our work, we also have emphasized the diversity of formats that could be included within this general consultation model, as found often in the area of parent training (e.g., Ollendick \& Cerny, 1981). For example, these authors reviewed training formats that can be used to teach parents behavior modification techniques to use with their children. These procedures have been called "didactic instruction" (Johnson \& Katts, 1973), "educational groups" (O'Dell, 1974), or "parent consultation" (Cobb \& Medway, 1978). Typically in these formats, parents were provided with information about behavior therapy techniques and may have been seen individually or in groups. Other formats were used as well in which the parent trainer/therapist met with parents one-on-one and supervised their practice with the child. We emphasize the issue as follows: "The point that we are making is that all three of these techniques may be considered a consultation approach. Any specific conclusions about the efficacy of consultation have to take into account this rather extensive parent-training literature. Of course, the same might be said about the teacher training literature, which in many areas runs parallel to the kinds of the formats used in parent training" (Bergan \& Kratochwill, 1990, p. 383). Finally, we went on to describe problems of defining specific models of behavioral consultation as represented in the literature. We specifically advocated that individuals who review behavioral consultation research outcomes embrace a broad perspective and include many indirect service delivery approaches that we have pointed to in the behavior therapy literature.

To further describe the evolution of thinking that pertains to some of these issues, Kratochwill, Sladeczek, and Plunge (1995) published an article on the evolution of behavioral consultation in the Journal of Educational and Psychological Consultation. It is unfortunate that this article was not mentioned in the Noell and Witt or Witt et al. articles. Evolution of thinking pertaining to reappraisal also takes place within the context of other literature that provides alternative conceptual frameworks for how consultation might be conducted in research and practice. Kratochwill et al. (1995) presented at least three types of approaches to be- 
havioral consultation that might be considered. Although it is beyond the scope of this article to outline these in great detail, it is important that these points be raised to alert readers to evolutionary options with regard to indirect service delivery technologies. In the article, we noted that the traditional case-centered consultation approach, although traditional in school psychology research, is one of several arrangements that might be used. Parent-based consultation that could be conducted in a conjoint fashion with teachers and other service providers (e.g., Sheridan \& Kratochwill, 1992; Sheridan, Kratochwill, \& Elliott, 1990) represents one option in this domain.

A second form of indirect service technology, especially important in the context of the present discussion, is technology training (Vernberg \& Reppucci, 1986). In this approach we noted that the framework expands consultation into technology training or a teaching methodology that could occur independently or jointly with the consultation problem solving process. We noted specifically that the approach emphasizes knowledge or information for the teacher consultee and could empower consultees to participate in the actual design of intervention programs. We also noted other options that incorporate child-based consultation or peer mediated formats are possible. The point of raising these issues is that they serve as a broad conceptual framework for how the conceptualization of consultation might be expanded within the context of the five traditional and "straw person" fundamental assumptions presented by Noell and Win (1996)

\section{FUNDAMENTAL ASSUMPTIONS REVISITED AND RE-EVALUATED}

\section{Assumption 1: Consultation Is a Superior Use of Resources When Compared to Direct Intervention}

Noell and Witt indicated that a fundamental assumption of behavioral consultation is that it is a superior use of resources when compared to direct intervention. Presumably, the intent here is to convey the message that mediator-based services may be less effective than direct intervention services. Two issues need to be taken into account to deal with this issue, namely, comparisons of direct and indirect services, and the empirical support for indirect services as an intervention. In the first case, comparative outcome research has been examined and interestingly, has represented an empirical direction in the behavior therapy field. For example, the classic study by Kelvin, Garside, Nicol, MacMillan, Wolstenholme, and Leitch (1981) focused on an evaluation of maladjusted children in schools and has been reviewed in greater detail in previous work on child therapy (see Kazdin, 1988). In the study, children were randomly assigned to one of four different conditions that varied by age. One condition involved parent counseling plus teacher consultation. As Kazdin (1988) noted, an interesting aspect of this study was its direct versus indirect feature. The direct treatments involved face-to-face interaction with the child such as group therapy. The indirect treatment consisted of working with significant oth- ers who in turn treated the child. Some tentative conclusions drawn from the study were that indirect treatment (i.e., the parent-teacher consultation) did not appear to produce major changes, whereas the more direct treatments that included behavior therapy and group therapy produced changes.

The point of mentioning this study is that it is certainly possible to evaluate particular models of service delivery. In doing this type of study, researchers must be very careful not to fall into the "therapy uniformity assumption myth," which assumes that a particular model of therapy is homogeneous with respect to broad categorical descriptors such as consultation versus direct intervention. These are constructs that need to be operationalized, and when they are - as we pointed out at the beginning of this article - one needs to take into account their focus. For example, will consultation be case-centered, technology training oriented, or focused on other dimensions of the process? What dimensions of direct intervention will be involved and what format will be used to define a direct intervention? Framing the issues in terms of broad variables will not address the range of options that must be examined in outcome research.

The second issue concerns the empirical support for indirect services as an intervention. Consistently, reviews of consultation research published since the mid-1970's reported positive findings (e.g., Gresham \& Kendell, 1987; Mannino \& Shore, 1975; Medway, 1979, 1982; Medway \& Updyke, 1985). In a recent review of outcome-based consultation research, Sheridan, Welch, and Orme (1996b) reported that at least some positive results were evident in $76 \%$ of consultation studies reviewed. Specific to the behavioral consultation outcome research, 95\% of the studies reported at least some positive findings, and of all results reported in the behavioral consultation literature, $89 \%$ were positive. This funding is particularly important in light of the fact that the behavioral consultation $(\mathrm{BC})$ research base has become increasingly rigorous over the past two decades (Sheridan et al., 1996b). Sheridan et al. concluded that "considering that the methodological standards are much more rigorous in $\mathrm{BC}$ studies than in those using other consultation models, it appears that BC yields the most favorable results" (p. 349).

A related issue pertains to the need to clarify the format (e.g., mediatorbased vs. direct) for treatments based on the empirical literature. The selection of a particular treatment technique should be based on the efficacy of the technique for a particular disorder or target problem, and not necessarily guided by the service delivery methodology. That is, certain forms of behavior therapy have documented efficacy pertaining to certain disorders (see Kratochwill and Morris, 1991 for an overview of a variety of behavior therapy techniques). Consider the parent mediated intervention work of Webster-Stratton, whose work is featured in the literature on empirically based treatments for externalizing disorders, aggression, or conduct disorders (see Webster-Stratton, 1996). In this area one might select her work, which we regard as one form of consultation-not because it involves indirect service delivery but because it has empirical support as a parent-mediated intervention. 
This point also can be nicely illustrated within the context of the therapeutic procedures used to treat selective mutism (Kratochwill, 1981). In a recent literature review and meta-analysis of various outcomes pertaining to treatment techniques (Pionek, Kratochwill, Sladezcek, \& Serlin, 1997), two findings were apparent. First, treatment was better than no treatment. Second, behavior therapy procedures, primarily because of their methodological focus and the ability to calculate effect sizes, were better than other therapeutic procedures that really could not be evaluated under the methodological and statistical criteria of the review. We were not able to make any specific conclusions about service delivery approaches, despite the fact that there are examples of effective outcome studies that have involved mediator-based models for this disorder (e.g., Piersel \& Kratochwill, 1982). A conclusion from reviewing this literature might be that a therapist would use some of the more commonly featured behavior therapy techniques such as stimulus fading to treat this disorder. He or she would not be provided further guidance regarding whether that therapy should be conducted by consulting and training mediators versus direct therapy. Nevertheless, a legitimate research direction might be to conduct a study in which mediators are trained to do the procedure and implement behavioral consultation as one option. Here the guidance for the model of application of the therapy would be the technique. Whether it is better done through direct implementation or indirect implementation might be best determined by an empirical practice model in which an evaluation during the course of the investigation takes place.

It is also important to note here that issues surrounding the nature and course of the target behavior and goals for consultation must also be considered in identifying the best course of treatment. Indeed, some behaviors simply do not lend themselves to direct therapy (e.g., certain low frequency or situation specific behaviors such as stealing) as readily as other behaviors. Further, behavior change goals must be more clearly articulated prior to indicating that one form of therapy is more or less effective than another. Here again, Noell and Witt (1996) and Witt et al. (1996a) continue to emphasize client-centered case consultation as the focus for debate. Alternative treatment goals or behaviors worthy of interventions might include system-level functions such as coordination of services or proficiency in mutual decision making. In these examples, indirect models seem better suited than individual focused, direct interventions. In a review of consultation outcome research conducted between 1985 and 1995, Sheridan et al. (1996b) found that $9 \%$ of the behavioral consultation studies addressed systematic (versus client or consultee) targets. The role of consultation in broad-based systematic interventions is a fertile area for empirical investigation.

Thus, although Noell and Witt (1996) note that behavioral consultation has not been compared to direct intervention, it is certainly possible to investigate this dimension of treatment given consideration to the other conceptual, methodological, and practical considerations of therapy outcome research. Given specification of what form of consultation is conducted and what form of therapy is used for what technique under what conditions would help further define a research agenda in this area. However, it is superficial and misguided to suggest that a major assumption guiding consultation is that it is superior in use of resources when compared to direct intervention.

\section{Assumption \#2: Consultation Is Most Effective When Conducted Collaboratively}

Noell and Witt (1996) are correct in noting that collaboration has been a common characteristic of a variety of models of consultation over the years (see Gutkin \& Curtis, 1990). Previously Witt (1990) raised issues pertaining to collaboration and Kratochwill (1991) provided a reaction to his points, raising the critical issue of first defining the dimensions of collaboration in research. Therefore, it is surprising that the issues in the Kratochwill (1991) article were not even raised in the discussion of collaboration in Noell and Witt (1996). In this regard, we would point to one way in which the concept of collaboration might be re-evaluated and re-conceptualized:

Perhaps it is best to reconceptualize the concept of collaboration as nondichotomous, considering that within the context of the consultation process, there are numerous dimensions of consultee collaboration in the problem-solving process (emphasis added). For example, the collaborative nature of a relationship may occur in terms of the teacher identifying a range of potential interventions that will work in his/her classroom setting. That is, a negotiated collaboration may develop given the consultants' effort to elicit effective intervention strategies. This dimensional representation of collaboration as a construct has merit considering the range of teacher ability and skill in a program of consultation. Of course, it may also be useful in making collaborative comparisons across consultee types such as teachers, parents, and peers. (Kratochwill, 1991, page 292)

Kratochwill (1991) also went on to indicate that Witt's concerns were primarily focused on the traditional case-centered form of behavioral consultation and did not take into account the broader framework (as outlined again in this article) that behavioral technology training, as well as behavioral systems consultation, would further extend the construct and result in a need to reformulate the definition of collaboration. Indeed, the manner in which "collaboration" has been defined by Witt and his colleagues is debatable. Therefore, it is important that readers reconsider their point and not reject collaborative models until the dimensions of collaboration have been redefined and reconceptualized along the lines of a more dimensional format.

For example, there may be important, functional outcomes associated with team-based consultation models wherein many participants engage in shared leadership roles (i.e., sharing information, observational data, expertise regarding various aspects related to problem definition and problem solution). In such 
practices, the consultant-consultee roles and responsibilities may shift, dependent upon important contextual information. Unfortunately, in a current review of teaming practices in schools, little empirical support for such approaches was found (Welch, Sheridan, \& Brownell, in preparation), suggesting the dire need for empirical research in this area. Nevertheless, all consultees can be empowered by providing specific training opportunities while maintaining certain features of collaboration (e.g., parity and interdependence). Thus we would emphasize the need to define collaborative work within the context of the different variations of consultation ranging from case-centered to systems approaches.

\section{Assumption 3: Talking to Teachers Is Sufficient to Cause Them to Change Their Behavior}

Noell and Witt (1996) raised a concern pertaining to using interview technology as a format for changing teacher behavior and issues related to teachers carrying out the actual treatment program. Witt et al. (1996a) expressed concern with the interview technology as being an indirect paradigm where heavy reliance is placed on verbal report within the context of problem assessment. Both of these issues involve "talking behaviors," and need to be discussed within the context of current advances in consultation research and the various options that extend beyond case-centered formats.

One of the first difficulties is that Witt and his associates have again limited their review of the literature to consultation articles appearing within the school psychology literature. Sheridan et al. (1996b) found that 33\% of behavioral consultation outcome studies conducted between 1985 and 1995 identified consultee variables as the target for intervention, and assessed consultee changes directly. Indeed, several studies have appeared, providing empirical support for implementing interventions in a consultation model-including case-centered consultation approaches. For example, in a study by Peck, Killen, and Baumgart (1989), consultation services were provided to teachers over the course of two experiments, and their use of instructional behaviors as targeted in the consultation sessions were assessed directly. What is interesting about these procedures is that there is a heavy reliance of the consultant on consultee input and selection of the intervention plan. Specifically, teachers were asked to identify independently strategies that they could use to address objectives on their students' Individualized Educational Plans (IEPs) during normal classroom instruction.

In one study, consultants refrained from providing specific techniques, although they provided positive feedback to consultees' suggestions. In the second experiment, consultants provided suggestions if teachers were unable to do so. Teachers in both experiments rank ordered the ideas that were generated and asked to select one or two to implement in a target academic setting. Emphasis was placed on teachers as the best judges regarding plan feasibility (emphasis theirs). Teachers in both studies demonstrated increases in instructional behaviors in targeted academic settings, and reported increased confidence in their ability to implement specialized instructional strategies. Students also demonstrated increases in the targeted behaviors. According to the authors, "a central feature of the consulting procedure (was) its reliance on ideas generated by regular classroom teachers as the primary strategies for implementing specialized instruction for students with handicaps. The role of the consultant (was) focused on clarifying the instructional needs of the child and facilitating the production of ideas by the regular teacher for meeting those needs" (p. 205; emphasis theirs).

A second difficulty pertains to the limited empirical technology currently available in the area of treatment integrity and its effects on behavioral outcomes. Northup et al. (1994) described a study wherein on-site technical assistance was provided to school personnel working in transdisciplinary teams. "Technical assistance" was described as "student-specific consultation, the development and modeling of specific interventions, and participation in... team meetings. All consultation was collaborative, and a choice of appropriate assessment and treatment procedures was provided in response to specific requests for direction" (p. 36). Results suggested that the intervention (functional communication training) was useful for addressing students' behavior problems, and that teachers were able to implement the procedures adequately (assessed via direct observation). However, there was a great degree of variability in the implementation of some aspects of the intervention. The authors raised the possibility that "there is a range of treatment that must be implemented with integrity to obtain meaningful results, although currently there is neither a rational nor an empirical basis for determining what that range might be ... it appears that integrity ... can vary substantially without total disruption of treatment effectiveness" (p. 46).

As we extend the model of consultation to parents and technology training, we can also provide some data pertaining to the influence on parent behavior. Carrington Rotto and Kratochwill (1994) examined the effects of an intervention strategy for child noncompliance, combining both case consultation with a competency-based parent training procedure that was labeled behavior technology training. Results of the study indicated that the treatment was effective in promoting skill acquisition to a mastery criterion for parents and decreasing child noncompliance at home. Some of the subsequent work in this area suggests that while parents acquire skills, this may not translate into behavior change for the child. Therefore, the issue of whether teachers and/or parents change their behavior as a function of the consultation process is an important one that should be measured. Given recent empirical work, we also need to reconsider the assumption that because teachers and/or parents change their behavior as a function of the intervention, this will automatically result in child behavior change, must be reexamined.

It is only in the past several years that researchers in the parent training literature have reconsidered important issues pertaining to the various models of working with parents. Competency-based approaches to skill acquisition and maintenance promote use of a predetermined level of competency for skill components 
that are the focus of the intervention. Parents might be taught skills to a criterion level that could serve as an important issue pertaining to whether the failure of child behavior change is due to parental (or teacher) skill or dimensions of the intervention itself.

A third issue that bears stating is the suggestion that lack of consultee behavior change occurs irrespective of consultant-consultee interactions. Consultant behaviors that are predictive of a consultee's actual use or nonuse of intervention strategies has not been explored in applied research. If consultants truly "control" consultation interactions, it is possible that certain consultant behaviors or verbalizations may maximize or minimize a consultee's effective use of intervention strategies.

The importance of consultation strategies in promoting consultee skill and child behavior change is illustrated in at least two studies that Noell and Witt (1996) and Witt et al. (1996a) failed to discuss. Regarding consultee skill in using an intervention effectively, McGimsey, Greene, and Lutzker (1995) found that only when behavioral trainers used behavioral consultation skills did parents use timeout strategies proficiently with their children, with concomitant positive child behavior change. Teaching the parents timeout applications using only behavior management knowledge was insufficient to change parents' behaviors; parent mastery required training from an individual proficient in the use of both behavior management and behavioral consultation. Although this study is in contrast to the findings of Carrington Rotto and Kratochwill (1994), it highlights the importance of both content and process knowledge and expertise in behavioral therapy.

Regarding the importance of consultation in promoting child behavior change, Galloway and Sheridan (1994) investigated the benefits of conjoint behavioral consultation (using parents and teachers as co-consultees) in promoting work completion and accuracy of primary grade students. In one condition, a behavioral consultant met with a parent and teacher and described the use of a structured home-note system with positive reinforcement. In a second condition, no consultation was provided, and parents and teachers used a manual to learn about and use the home-note. Greater and more stable gains were found, treatment integrity (assessed by both self-report and permanent products), and acceptability of the intervention were higher in the $\mathrm{CBC}$ condition than in the manual/note condition only. This study highlighted the importance of consultation as a means of supporting consultee treatment integrity and positive client outcomes.

\section{Assumption \#4: Teachers Will Generalize Problem-Solving Skills Developed} in Consultation to New Problem Situations with Other Students

As Noell and Witt (1996) correctly indicate. Assumption \#4 is a slightly different dimension of the same issue raised in Assumption \#3. The issue of whether teachers and other mediators generalize problem-solving skills to new problem situations and other clients certainly does remain to be empirically demon- strated. We would also note that, in addition to the Carrington Rotto and Kratochwill (1994) study, competency-based training might facilitate generalization to new problem situations and other clients. However, some consultation research is available that addresses this very issue. A study by Peck et al. (1989) that we described earlier directly assessed teachers' generalization of effective instructional strategies to academic areas not targeted in consultation. The authors found that across the two experiments, four of five teachers effectively and independently generalized their skills (i.e., use of strategies) to nontargeted settings.

We also point to what we regard as an important, but unpublished, dissertation conducted a number of years ago by Hazzard. In the study (Hazzard, Bergan, $\&$ Kratochwill, 1995) the effects of behavioral consultation on teacher application and transfer of behavior management strategies were evaluated. The manuscript was unfortunately rejected, even though it is the only investigation we know of to address the issue of the generalizability of behavioral consultation interventions through verbal prompts. In the study, a behavioral consultation intervention package that utilized interviews to impact teacher and child behaviors was assessed in a multiple baseline design. Subsequent to the consultation interviews, three teachers implemented a reinforcement-based intervention to modify engaged time of children "referred" for these problems. Hazzard also had three referred but "nontargeted" children and three "non-referred" children concurrently measured to assess the effects of the program. Results of the study indicated that the consultation interview package successfully changed teacher and child behavior of the referred children. Specific prompting and cuing, however, were necessary to generalize the program to referred non-targeted children and unfortunately, from the standpoint of consultation interventions, no generalization to non-referred children occurred. The study did indicate that verbal prompting could influence teacher behavior and therefore, facilitate the implementation of an intervention with these children. Thus, further prompting may be necessary to encourage the teacher to generalize to non-referred children who might profit from the intervention program.

\section{Assumption \#5: Direct Contact Between the Consultant and Client is Unnecessary}

Noell and Witt (1996) and Witt et al. (1996a) raised a concern pertaining to the process of consultation, inasmuch as it is perceived as an indirect paradigm where heavy reliance is placed on verbal report from teachers or other mediators. Behavioral consultation was developed within the context of a verbal process model, wherein the type of interaction was structured to yield specific outcomes in a problem-solving process (Bergan, 1977). The same verbal process served as a conceptual overlay for problem-solving activities in consultation in the recent edition of Bergan and Kratochwill (1990). We placed much less emphasis in practice on the specific verbal processes in consultation and more on general or global objectives pertaining to accomplishing specific activities associated with the inter- 
view structure used in consultation (e.g., Kratochwill \& Bergan, 1990; Sheridan et al., 1996a).

Verbal interactions as an assessment tactic represent an indirect method for gathering data within traditional conceptualizations of behavioral consultation and assessment (see Kratochwill \& Shapiro, 1987). We are quite aware of these limitations and appreciate many of the arguments advanced over the years related to this issue. What is puzzling, however, is the emphasis that these authors place on "verbal interaction" as a sole assessment method used in behavioral consultation. Our early work (e.g., Bergan \& Kratochwill, 1990) and recent publications (i.e., Sheridan et al., 1996a) place behavior interviews within a more comprehensive behavioral assessment framework. Indeed, a teacher's verbal report does not occur in a vacuum. Such a criticism suggested a passive, nonparticipatory consultant role - a role that is not borne out in the literature.

Many of the arguments raised by Noell and Witt (1996) and Witt et al. (1996a) reflect consultation research wherein limited assessment of outcomes has occurred, and not problems inherent within behavioral consultation as a research valid, service-delivery model. Good consultation research and practice dictate broadening assessment in many cases to include direct observations, behavioral checklists, and other methods across all problem-solving stages. Many examples can be provided that support our contention that Noell and Witt (1996) and Witt et al. (1996a) again neglected or misrepresented contemporary literature on this topic. In fact, Sheridan et al. (1996) found that of 21 empirical outcome studies in behavioral consultation reported between 1986 and 1995, 52\% used multiple measures and $76 \%$ used direct observations to assess consultation outcomes. Likewise, in an article not reviewed by Noell and Witt (1996) and Witt et al. (1996a), Sheridan (1992) stated that "information about individual students, the curriculum, and the classroom ecology is relevant and pertinent to understanding and intervening in a case...in the spirit of best practices in ecological assessment, multimethod procedures ... are critical to our success in consultation" (p. 91).

There are two additional issues we would raise within the context of the use of indirect assessment strategies. First, there is the question of whether empirical data can provide information regarding the treatment utility of verbal approaches that lead to change in teacher behavior and ultimately and importantly, child behavior. A second issue pertains to whether "systematic verbal interactions" are part of the proposed alternative problem-solving assessment that leads eventually to intervention. Let us address each of these points in turn.

Despite heavy reliance on verbal communication in the practice of most consultation models, there is a paucity of research focused on evaluating relations among verbal interactions and teacher and child outcomes. Most recently, Busse, Kratochwill, and Elliott (1997) addressed the issue in a study designed to investigate the relations among consultant and consultee verbal behaviors and consultation treatment outcomes. Specifically, the project included 24 graduate student consultants, 26 teacher consultees, and over 102 children with various academic and behavioral problems. The independent variables in the study involved categories of verbal behavior from the Consultation Analyses Record (CAR). The dependent variables were consultee perceptions of consultant effectiveness, treatment outcome indices on convergent evidence scaling (CES), and effect size based on single-case meta-analysis tactics. We found that consultants followed general guidelines for the occurrences of verbalizations within consultation. That is, they matched general objectives within consultation with those specified in the CAR. We also found that consultants exerted control over the consultation process, a finding consistent with the behavioral consultation model (despite a number of previous misinterpretations of behavioral consultation as "collaborative" but again, see Kratochwill, 1991).

More important for our present purposes, we conducted a series of multiple regressions to test a hypothesized model that consultant control, behavior specification, plan specification, and consultee positive validation would account for significant variance in child treatment outcomes. We found that consultant control was predictive of perceptions of consultant effectiveness, but not predictive of child outcomes. Efficient use of behavior and plan specification statements, however, were predictive of positive outcomes. The predicted model accounted for $34 \%$ of the variance on outcomes. The study is important in the context of evaluating the level at which we should begin to analyze consultants' verbal behaviors, or whether there are other variables that have a more specific impact on treatment outcome. We interpret the results from this study to indicate that verbal interactions play a significant role in successful treatment outcomes.

Our second issue pertaining to the use of verbal behaviors in problem solving challenges the assumption that alternative approaches do not rely on verbal techniques to gather data and implement treatments. Virtually all models of consultation and even more traditional direct behavior therapies, as well as functional analyses as recommended by Witt et al. (1996a), rely heavily on verbal behaviors during the course of assessment. It is puzzling that a methodology has not been explored to establish important accuracy, reliability, and validity indices related to verbal interactions that occur as part of these problem solving processes. That is, we would point out that many of the assessment and intervention tactics applied in practice include verbal behaviors. One can hardly imagine any intervention tactics described in research, or those used most commonly in the field of behavior analysis, that would not rely on some level of verbal interchange. The issue is that there has been a noticeable lack of information on what verbalizations do take place. Given that we can analyze these as behaviors in their own right, we may come to understand the problems pertaining to the lack of reliability, validity, and treatment utility in some of our assessment and intervention technologies

Also implicit in Assumption \#5 (and more strongly stated by Witt et al., 1996a) was that more traditional problem analysis be replaced by functional analysis. We agree with the potential of this tool and believe that important advances have occurred in applications of functional analysis in the field of applied behav- 
ior analysis (e.g., Haynes \& O’Brien, 1990; Neef \& Iwata, 1994; O’Neill, Homer Albin, Sprague, Storey, \& Newton, 1990; Schill, Kratochwill, \& Gardner, 1996a). Our most recent work includes recommendations for the application of functional analysis in conjoint consultation (Sheridan et al., 1996a). Although we are aware of the potential power of functional analysis, methodology of functional analysis consists of a potentially wide range of applications that include (a) descriptive assessment, which might involve indirect assessment methods such as interviews, checklists, and rating scales, and (b) hypothesized functional relationships that could be tested with analog experimental assessment or direct assessment. Functional analysis could also be implemented by the consultant directly or by one of many mediators, such as teachers or parents. In the latter case, verbal interchange for purposes of training is common. It is beyond the scope of our response to review functional analysis in detail, and the interested reader should refer to the special series in the Journal of Applied Behavior Analysis (see Neef \& Iwata, 1994; O’Neill et al., 1990) as well as some recent discussions (e.g., Schill et al., 1996a; Vollmer \&Northup, 1996).

Several particular features of functional analysis should be noted. To begin with, methods of functional analysis vary widely and future researchers should focus on the relationship among different tactics of functional analysis to determine their compatibility as well as their comparability across alternative assessment targets and methodologies. Second, if functional analysis is to be used increasingly within consultation approaches it may add considerable time to the consultation process. The first author, Thomas R. Kratochwill, and his associates have applied functional analysis in several different cases, one of which involved assessmen of a case of selective mutism (Schill, Kratochwill, \& Gardner, 1996b). We would emphasize that some of the same concerns pertaining to integrity of implementation of functional analysis occur as they do in any other assessment and intervention techniques, including consultation. We should not be fooled into a false sense of security in adopting "new" assessment technologies without due consideration to problems that we have experienced in the past with conventional assessment and treatment technologies (Kratochwill \& McGivern, 1996). Finally, we would raise an important issue related to the applications of functional analysis. The interventions associated with the methodology appear somewhat narrow, although applications are expanding in this area (e.g.. Repp, Karsh, Munk, \& Dahlquist, 1995). Many of the traditional interventions appear linked to specific operant techniques, such as positive and negative reinforcement. These tactics may provide a rather limited range of applications to treatment techniques for what could be complex problems and issues that confront individuals working as consultants in applied settings. For example, much research on functional analysis has focused on aberrant behavior, with less attention devoted to instructional variables and instructional ecology in classrooms. In addition, many functional analysis tactics that have been implemented in applied settings have served a management or behavior control function. Intervention tactics that prevent the occurrences of academic and behavioral problems might be a productive strategy to consider in terms of applications of functional assessment and interventions.

We would also hope the field would embrace a broader technology in theoretical paradigms for implementation of interventions in applied settings. There are some important developments occurring in a variety of fields, one of which involves the development of empirically based treatments (e.g., Hibbs \& Jensen, 1996; LeCroy, 1994). An impressive range of treatment techniques have been developed for a variety of child and adolescent problems, including for example, anxiety disorders, attention deficit hyperactivity disorder, disruptive behavior and conduct disorders, and childhood autism. Although functional analysis may have been an important part of some of the early research work in these areas, many of the empirically based treatments are implemented as a technology and may not require functional analysis prior to their application (see Braden \& Kratochwill, 1997).

\section{SUMMARY}

Noell and Witt (1996) conclude that the fundamental assumptions of behavioral consultation have remained static for at least 19 years. In the past several years, we have read literature and conducted research that would cast doubt on their final summary statement. The points we have raised here do not just cast doubt on the scientific quality and credibility of Noell and Win's original arguments, but will hopefully have a broader impact of stimulating the very research issues they set out to feature - unfortunately from a limited knowledge-base. Regretfully, despite all that Noell and Witt have said and done on the topic of behavioral consultation assumptions, more has been done than they have said. We hope our reactions are seen as constructive and change what they claim and actually publish in the future.

\section{REFERENCES}

Bergan, J. R. (1977). Behavioral consultation. Columbus, OH: Charles E. Merrill.

Bergan, J. R. (1995). Evolution of a problem-solving model of consultation. Journal of Educational and Psychological Consultation, 6, 111-123.

Bergan, J. R., \& Kratochwill, T. R. (1990). Behavioral consultation and therapy. New York: Plenum Press.

Braden, J. P., \& Kratochwill, T. R. (1997). Treatment utility of assessment: Myths and realities. School Psychology Review, 26, 475-485.

Busse, R. T., Kratochwill, T. R., \& Elliott, S. N. (1997). The influence of verbal interactions during consultations on treatment outcomes. Manuscript submitted for publication.

Carrington Rotto, P., \& Kratochwill, T. R. (1994). Behavioral consultation with parents: Using competency-based training to modify child noncompliance. School Psychology Review, 23, 669-693. 
Cobb, D. E., \& Medway, F. J. (1978). Determinants of effectiveness in parent consultation. Journal of Community Psychology, 6, 229-240.

Ehrhardt, K. E., Barnett, D. W., Lentz, F. E., Jr., Stoller, S. A., \& Reifin, L. H. (1996). Innovative methodology in ecological consultation: Use of scripts to promote treatment acceptability and integrity. School Psychology Quarterly, 11, 149-168.

Erchul, W. P., \& Schulte, A. C. (1996). Behavioral consultation as a work in progress: A reply to Witt, Gresham, and Noell. Journal of Educational and Psychological Consultation.

Galloway, J., \& Sheridan, S. M. (1994). Implementing scientific practices through case studies: Examples using home-school interventions and consultation. Journal of School Psychology, $32,385-413$.

Gresham, F. M. (1991). Whatever happened to functional analysis in behavioral consultation? Journal of Educational and Psychological Consultation, 2, 387-392.

Gutkin, T. B., \& Curtis, M. J. (1990). School-based consultation: Theory, techniques, and research. In T. B. Gutkin \& M. J. Curtis (Eds.), The handbook of school psychology (2nd ed., pp. 577-611). New York: Wiley.

Haynes, S. N., \& O'Brien, W. H. (1990). Functional analysis in behavior therapy. Clinical Psychology Review, 10, 649-668.

Hazzard, J. E., Bergan, J. R., \& Kratochwill, T. R. (1995). The effects of behavioral consultation on teacher application and transfer of behavior management principles. Unpublished manuscript, University of Arizona, Tucson, AZ.

Hibbs, E. D., \& Jensen, P. S. (Eds.) (1996). Psychosocial treatments/or child and adolescent disorders: Empirically-based strategies for clinical practice. Washington, DC: American Psychological Association.

Johnson, C. A., \& Katz, R. C. (1973). Using parents as change agents for their children: A review. Journal of Clinical Psychology and Psychiatry, 14, 181-200.

Kazdin, A. E. (1988). Child psychotherapy: Developing and identifying effective treatments. New York: Pergamon.

Kolvin, I., Garside, R. F., Nicol, A. R., MacMillan, A., Wolstenholme, F., \& Leitch, I. M. (1981). Help starts here: The maladjusted child in the ordinary school. London: Tavistock.

Kratochwill, T R. (1991). Defining constructs in consultation research: An important agenda in the 1990s. Journal of Educational and Psychological Consultation, 2, 291-294.

Kratochwill, T. R., \& Bergan, J. R. (1990). Behavioral consultation in applied settings. New York: Plenum.

Kratochwill, T. R., \& McGivern, J. E. (1996). Clinical diagnosis, behavioral assessment, and functional analysis: Examining the connection between assessment and intervention. School Psychology Review, 25, 342-355.

Kratochwill, T. R., \& Morris, R. M. (Eds.). (1991). The practice of child therapy (2nd ed). New York: Pergamon.

Kratochwill, T. R., \& Shapiro, E. S. (1988). Introduction: Conceptual foundations of behaviora assessment in schools. In E. S. Shapiro \& T. R. Kratochwill (Eds.), Behavioral assessment in schools: Conceptual foundations and practical applications (pp. 1-13). New York: Guilford Press.

Kratochwill, T. R., Sladeczek, I., \& Plunge, M. (1995). The evolution of behavior consultation. Journal of Educational and Psychological Consultation, 6, 145-157.

LeCroy, C. (Ed.) (1994). Handbook of child and adolescent treatment manuals. New York: Lexington Books.
Mannino, F. V., \& Shore, M. F. (1975). The effects of consultation: A review of the literature. American Journal of Community Psychology, 3, 1-21.

McGimsey, J. F., Greene, B. F., \& Lutzker, J. R. (1995). Competence in aspects of behavioral treatment and consultation: Implications for service delivery and graduate training. Journal of Applied Behavior Analysis, 25, 301-315.

Medway, F. J. (1979). How effective is school consultation? A review of recent research. Journal of School Psychology, 77, 275-282.

Medway, F. J. (1982). School consultation research: Past trends and future directions. Professional Psychology, 13, 422-430.

Medway, F. J., \& Updyke, J. F. (1985). Meta-analysis of consultation outcome studies. American Journal of Community Psychology, 13, 489-505.

Munk, D. D., \& Repp, A. C. (1994). The relationship between instructional variables and problem behavior: A review. Exceptional Children, 60, 390-401.

Neef, N. A., \& Iwata, B. A. (1994). Current research on functional analysis methodologies: An introduction. Journal of Applied Behavior Analysis, 27, 211-214.

Noell, G. H., \& Witt, J. C. (1996). A critical re-evaluation of five fundamental assumptions underlying behavioral consultation. School Psychology Quarterly, 11, 189-203.

Northup, J., Wacker, D. P., Berg, W. K., Kelly, L., Sasso, G., \& DeRaad, A. (1994). The treatment of severe behavior problems in school settings using a technical assistance model. Journal of Applied Behavior Analysis, 27, 33-47.

O'Dell, S. (1974). Training parents in behavior modifications: A review. Psychological Bulletin. 8, 418-433.

Ollendick, T. H., \& Cerny, J. A. (1981). Clinical behavior therapy with children. New York: Pergamon Press.

O’Neill, R. E., Homer, R. H., Albin, R. W., Storey, K., \& Sprague, J. R. (1990). Functional analysis of problem behavior: A review. Exceptional Children, 60, 390-401.

Peck, C. A., Killen, C. C., \& Baumgart, D. (1989). Increasing implementation of special education instruction in mainstream preschools: Direct and generalized effects of nondirective consultation. Journal of Applied Behavior Analysis, 22, 197-210.

Piersel, W. C., \& Kratochwill, T. R. (1982). A teacher-implemented contingency management package to assess and treat selective mutism. Behavioral Assessment, 3, 371-382.

Pionek, B. C., Kratochwill, T. R., Sladeczek, I., \& Serlin, R. C. (1997). Treatment of selective mutism: A best-evidence synthesis. Manuscript submitted for publication.

Repp, A. C., Karsh, K. G., Munk, D., \& Dahlquist, C. M. (1995). Hypothesis-based interventions: A theory of clinical decision-making. In W. O'Donohue \& L. Krasner (Eds.), Theories of behavior therapy: Exploring behavior change (pp. 585-608). Washington DC: American Psychological Association.

Schill, M. T., Kratochwill, T. R., \& Gardner, W. I. (1996a). Conducting a functional analysis of behavior. In M. J. Breen \& C. R. Fiedler (Eds.), Behavioral approach to assessment of youth with emotional/behavioral disorders (pp. 83-179). Austin, TX: Pro-Ed.

Schill, M. A., Kratochwill, T. R., \& Gardner, W. I. (1996b). An assessment protocol for selective mutism: Analogue assessment using parents as facilitators. Journal of Selective Psychology, $34,1-21$.

Sheridan, S. M. (1992). What do we mean when we say "collaboration"? Journal of Educational and Psychological Consultation, 3, 89-92. 
Sheridan, S. M., Kratochwill, T. R., \& Bergan, J. R. (1996a). Conjoint behavioral consultation: A procedural guide. New York: Plenum.

Sheridan, S. M., Kratochwill, T. R., \& Elliott, S. N. (1990). Behavioral consultation with parents and teachers: Delivering treatment for socially withdrawn children at home and school. School Psychology Review, 19, 33-52.

Sheridan, S. M., Welch, M., \& Orme, S. F. (1996b). Is consultation effective? A review of outcome research. Remedial and Special Education, 17, 341-354.

Vernberg, E. M., \& Reppucci, N. D. (1986). Behavioral consultation. In F. V. Mannino, E. J. Tickett, M. F. Shore, M. G. Kidder, \& G. Levin (Eds.), Handbook of mental health consultation (pp. 49-80). Washington, DC: National Institute of Mental Health.

Vollmer, T. R., \& Northup, J. (1996). Some implications of functional analysis for school psychology. School Psychology Quarterly, 11, 76-92.

Webster-Stratton, C. H. (1996). Early intervention with videotape modeling: Programs for families of children with oppositional defiant disorder or conduct disorder. In E. D. Hibbs \& P. S. Jensen (Eds.), Psychosocial treatments/or child and adolescent disorders: Empirically based strategies for clinical practice (pp. 435-474). Washington, DC: American Psychological Association.

Welch, M., Sheridan, S. M., \& Brownell, K. (In preparation). What's the score on teaming in schools? A review of the literature on team teaching and school-based problem solving teams.

Witt, J. C. (1990). Complaining, precopernican thought and the univariate linear mind: Questions for school-based behavioral consultation research. School Psychology Review, 19, 367-377.

Witt, J. C., Gresham, F. M., \& Noell, G. H. (1996a). What's behavioral about behavioral consultation? Journal of Educational and Psychological Consultation,

Win, J. C., Gresham, F. M., \& Noell, G. H. (1996b). The effectiveness and efficiency of behavioral consultation: Differing perspectives about epistemology and what we know. Journal of Educational and Psychological Consultation,

Witt, J. C., \& Martens, B. K. (1988). Problems with problem-solving consultation: A reanalysis of assumptions, methods, and goals. School Psychology Review, 77, 211-226.

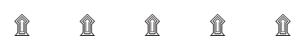

The "Action Editor" for School Psychology Quarterly was Joseph C. Witt; this paper was accepted July 25, 1997. 